\title{
Extent and distribution of calcification of both the aortic annulus and the left ventricular outflow tract predict aortic regurgitation after transcatheter aortic valve replacement
}

\author{
Lutz Buellesfeld ${ }^{1 *}$, MD; Stefan Stortecky ${ }^{1}, \mathrm{MD}$; Dik Heg${ }^{2}$, PhD; Steffen Gloekler ${ }^{1}, \mathrm{MD}$; Bernhard Meier ${ }^{1}$, MD; \\ Peter Wenaweser ${ }^{1}$, MD; Stephan Windecker ${ }^{1,2}$, MD \\ 1. Department of Cardiology, Swiss Cardiovascular Center, Bern University Hospital, Bern, Switzerland; 2. CTU Bern, \\ Department of Clinical Research, and Institute of Social and Preventive Medicine (ISPM), University of Bern, Bern, Switzerland
}

L. Buellesfeld and S. Stortecky contributed equally to this manuscript.

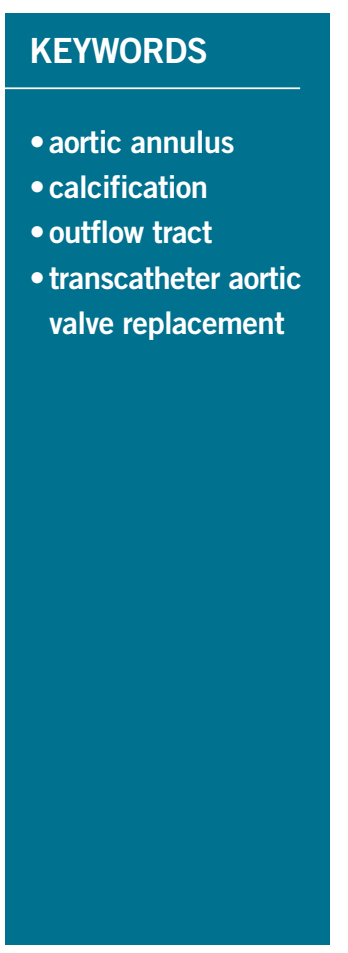

\begin{abstract}
Aims: We sought to analyse local distribution of aortic annulus and left ventricular outflow tract (LVOT) calcification in patients undergoing transcatheter aortic valve replacement (TAVR) and its impact on aortic regurgitation (AR) immediately after device placement.
\end{abstract}

Methods and results: A group of 177 patients with severe aortic stenosis undergoing multislice computed tomography of the aortic root followed by TAVR were enrolled in this single-centre study. Annular and LVOT calcifications were assessed per cusp using a semi-quantitative grading system (0: none; 1 [mild]: small, non-protruding calcifications; 2 [moderate]: protruding [ $>1 \mathrm{~mm}]$ or extensive [ $>50 \%$ of cusp sector] calcifications; 3 [severe]: protruding and extensive calcifications). Any calcification of the annulus or LVOT was present in 107 (61\%) and 63 (36\%) patients, respectively. Prevalence of annulus/LVOT calcifications in the left coronary cusp was $42 \%$ and $25 \%$, respectively, in the non-coronary cusp $28 \%$ and $13 \%$, in the right coronary cusp $13 \%$ and $5 \%$. AR grade 2 to 4 assessed by the method of Sellers immediately after TAVR device implantation was observed in 55 patients (31\%). Multivariate regression analysis revealed that the overall annulus calcification (OR [95\% CI] 1.48 [1.10-2.00]; $\mathrm{p}=0.0106)$, the overall LVOT calcification (1.93 [1.262.96 ]; $\mathrm{p}=0.0026$ ), any moderate or severe LVOT calcification (5.37 [1.52-18.99]; $\mathrm{p}=0.0092)$, and asymmetric LVOT calcification were independent predictors of AR.

Conclusions: Calcifications of the aortic annulus and LVOT are frequent in patients undergoing TAVR, and both the distribution and the severity of calcifications appear to be independent predictors of aortic regurgitation after device implantation.

\footnotetext{
*Corresponding author: Department of Cardiology, Swiss Cardiovascular Center Bern, Bern University Hospital, 3010 Bern, Switzerland.E-mail: lutz.buellesfeld@insel.ch
} 


\section{Introduction}

The presence of calcifications is a characteristic finding of degenerative aortic valve stenosis which becomes more pronounced with advanced disease stages. Among patients undergoing transcatheter aortic valve replacement (TAVR), aortic valve calcification has been identified as a predictor of paravalvular regurgitation after device placement ${ }^{1-10}$. However, little is known about the spatial distribution of aortic valve calcifications on the annular and particularly the left ventricular outflow tract (LVOT) level as well as its

\section{Editorial, see page 659}

clinical impact. Current devices anchor and seal within the annulus and LVOT, and therefore localised calcifications within these regions may play an important role and may affect the procedural outcome. Therefore, the aim of this study was to assess systematically the extent, distribution, and localisation of annulus and LVOT calcifications in patients undergoing TAVR and to analyse their impact on the frequency and severity of immediate aortic regurgitation (AR) after device implantation.

\section{Methods}

\section{PATIENT POPULATION}

A consecutive group of patients with severe aortic stenosis evaluated for TAVR by multislice computed tomography (MSCT) imaging of the aortic root and subsequent TAVR procedure were enrolled in this single-centre observational study between October 2007 and March 2012. All patients had an increased surgical risk or were deemed inoperable due to significant pre-existing clinical conditions and comorbidities. The assessment was performed by the institutional Heart Team and the decision to perform TAVR based on a consensus. All patients provided written informed consent to be included in both the local and national TAVR registries which were approved by the local ethics committee.

\section{IMAGING TECHNIQUE}

MSCT assessment of the aortic root was performed on either a Siemens SOMATOM Sensation Cardiac 64 scanner with a slice collimation of $1.5 \mathrm{~mm}$, or a Siemens SOMATOM Definition Flash Dual Source scanner with a slice collimation of $0.6 \mathrm{~mm}$, tube voltage of 100 or $120 \mathrm{kV}$ and tube current according to patient size (Siemens Medical Solutions, Inc., Forchheim, Germany). All patients underwent contrast-enhanced MSCT scanning with retrospective ECG gating and received an intravenous injection of 80 to $120 \mathrm{ml}$ of contrast medium via the antecubital vein at a flow rate of $5 \mathrm{ml} / \mathrm{s}$. Automated peak enhancement detection in the descending aorta at the level of the diaphragm with a threshold of 100 Hounsfield units was used for timing of the scan. Images were reconstructed in the diastolic phase at $60 \%$ of the RR interval.

Images were processed offline at a dedicated workstation using the semi-automated 3mensio tool (3mensio Medical Imaging BV, Bilthoven, The Netherlands). After automated segmentation of the aortic root, the annular plane was manually identified in a perpendicular short-axis view, defined as the plane connecting the nadirs of the three aortic cusps. The LVOT plane was defined as a plane perpendicular to the centre line $5 \mathrm{~mm}$ below the annular plane ${ }^{11}$. The analyses were performed by an experienced observer who was blinded to clinical and echocardiographic as well as procedural data.

\section{DEFINITION OF CALCIFICATION GRADING}

The degree of calcification was graded at both the annular and the LVOT level, and assessed per cusp sector. The extent of the virtual cusp sector in the annular and LVOT plane was defined by the actual extent of the corresponding cusp and named accordingly (Figure 1). The calcification was semi-quantitatively graded as follows: grade 0 - no calcification, grade 1 - small, non-protruding calcifications, grade 2 - protruding $(>1 \mathrm{~mm})$ or extensive $(>50 \%$ of cusp sector) calcifications, grade 3 - protruding $(>1 \mathrm{~mm})$ and extensive ( $>50 \%$ of cusp sector) calcifications (Table 1$)$. Grading examples are displayed in Figure 1, representative of both the annular and the LVOT plane. "Any calcification" was defined as the presence of calcification grade 1-3 in at least one of the three cusp sectors within the annulus and the LVOT, respectively. "Overall calcification" was defined as the sum of all three cusp sectors in a particular level. The overall valve calcification including leaflets was visually graded per cusp as none $=0$, mild $=1$, moderate $=2$ and severe $=3$, and was derived from the $3 \mathrm{D}$ MSCT reconstruction of the aortic root in the maximum intensity projection.
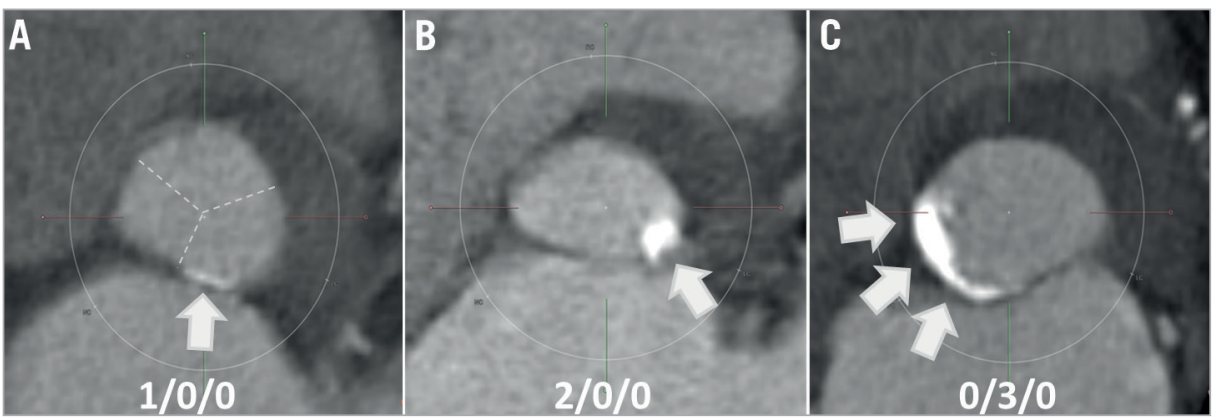

Figure 1. Examples of annulus/LVOT calcification types. A) Mild calcification of left coronary sector, absence of calcifications in non and right coronary sectors (type 1/0/0). Dotted lines indicate cusp sectors, which are identified from a parallel valvular plane. B) Moderate calcification of left coronary sector, absence of calcifications in non and right coronary sectors (2/0/0). C) Severe calcification of noncoronary sector, absence of calcifications in left and right coronary sectors (0/3/0). LVOT: left ventricular outflow tract 
Table 1. Definition of cusp-specific annulus and LVOT calcification grading.

\begin{tabular}{|l|l|}
\hline Grade 0 & No calcification \\
\hline Grade 1 (mild) & Small, non-protruding calcification \\
\hline Grade 2 (moderate) & $\begin{array}{l}\text { Protruding (>1 mm) or extensive ( }>50 \% \text { of } \\
\text { cusp sector) calcification }\end{array}$ \\
\hline Grade 3 (severe) & $\begin{array}{l}\text { Protruding }(>1 \mathrm{~mm} \text { ) and extensive (>50\% of } \\
\text { cusp sector) calcification }\end{array}$ \\
\hline LVOT: left ventricular outflow tract \\
\hline
\end{tabular}

\section{ASSESSMENT OF POST-IMPLANT AORTIC REGURGITATION}

AR was assessed immediately after implantation of the TAVR prosthesis by means of a standardised supra-aortic angiography using contrast dye injection through a $5 \mathrm{Fr}$ pigtail catheter $(40 \mathrm{ml}$ at 15 to $20 \mathrm{ml} / \mathrm{sec}$ ) positioned $1.5-2 \mathrm{~cm}$ above the aortic valve in a posterior-anterior or right anterior-oblique projection, based on the criteria established by Sellers. Patients with no and mild AR (grade 0 and 1) and patients with more than mild AR (grade 2-4) were grouped in two cohorts and compared with regard to baseline clinical characteristics, echocardiographic status and MSCT geometric characteristics as well as differences in calcification patterns. The endpoint of immediate post-implant AR instead of final post-procedural AR was intentionally selected to allow for identification of anatomic characteristics which predict suboptimal immediate device performance.

\section{STATISTICAL ANALYSIS}

Categorical variables are presented as counts with percentages ( $p$-values from chi-square or Fisher's tests), continuous variables as means with standard deviations ( $p$-values from t-tests), or as medians and 25\%-75\% interquartile ranges ( $\mathrm{p}$-values from Mann-Whitney $\mathrm{U}$ tests). Calcification effects on AR after implantation (moderate or severe coded 1 , none or mild coded 0 ) were analysed using logistic regressions and graphically presented as probabilities (95\% confidence interval $[\mathrm{CI}]$ ) with the model fitted line. There was no evidence of differential calcification effects on AR comparing the three different cusps (all pairwise comparisons of effects sizes $p>0.18$ ), so the calcification grades of the three cusps were aggregated or summed as appropriate for the final analyses (e.g., any calcification means at least one cusp with mild, moderate or severe calcification; e.g., overall calcification means the grade of the three cusps added). To assess the potential effect of asymmetric cusp calcification, we also estimated the effect of the difference in the calcification grade among the three cusps ( $\geq 1$ or $\geq 2$ grade difference between the three cusps). Models were compared using Akaike's Information Criterion (AIC; presented with odds ratios [OR] 95\% CI), corrected for valve calcification, device implantation height and device to annulus ratio. All statistical analyses were performed with Stata 12.1 (StataCorp LP, College Station, TX, USA).

\section{Results}

A total of 188 patients (mean age $82.2 \pm 5.8$ years, STS predicted risk of mortality $6.1 \pm 3.9$ ) were screened for inclusion in the study. Eleven patients were excluded because of insufficient MSCT imaging quality due to respiration artefacts which did not allow for a precise delineation of calcifications and corresponding cusp sectors. Therefore, the overall study population comprised 177 patients. Baseline patient characteristics are presented in Table 2.

\section{Calcification distribution}

Any calcifications of the aortic valve were observed in 174 patients (98\%). Calcifications of the annulus and LVOT were observed in 107 $(61 \%)$ and $63(36 \%)$ patients, respectively. More than mild calcifications were present in 29 (16\%) patients within the annulus and 13 (7\%) patients within the LVOT. Calcifications were most frequently located within the left coronary cusp with a prevalence of $42 \%$ for the annulus and $25 \%$ for the LVOT, followed by the non-coronary cusp $(28 \% / 13 \%)$ and the right coronary cusp (13\%/5\%) (Figure 2).

\section{Procedural characteristics and results}

TAVR was performed using the transfemoral access in 145 patients $(82 \%)$, transapical in $29(16 \%)$ and subclavian access in three patients $(2 \%)$. Device success according to the VARC-2 definition was achieved in $96.6 \%$ of patients. The self-expanding Medtronic CoreValve (Medtronic, Minneapolis, MN, USA) prosthesis was implanted in 112 patients (63\%), whereas the Edwards SAPIEN/ SAPIEN XT (Edwards Lifesciences, Irvine, CA, USA) prosthesis was implanted in 65 patients (37\%). AR grade 2 to 4 immediately after TAVR was observed in 55 patients $(31 \%)$, which resulted in postdilation in 50 and implantation of a second device in five patients. The final grade of AR was 0 in 41 (23\%), 1 in 95 (54\%), 2 in $39(22 \%)$ and 3 in two patients (1\%). Comparing patients with and without AR of grade 2 to 4 immediately after TAVR, there were no differences in terms of the device used $(\mathrm{p}=0.157)$, implantation depth at the non-coronary ( $6.1 \pm 3.2 \mathrm{~mm}$ vs. $5.4 \pm 2.9 \mathrm{~mm}$; $\mathrm{p}=0.151)$ and left coronary cusp level $(6.6 \pm 3.5 \mathrm{~mm}$ vs. $6.3 \pm 3.2 \mathrm{~mm} ; \mathrm{p}=0.562)$, pre-procedural aortic valve area $\left(0.6 \pm 0.2 \mathrm{~cm}^{2}\right.$ vs. $\left.0.6 \pm 0.2 \mathrm{~cm}^{2} ; \mathrm{p}=0.174\right)$ and left ventricular

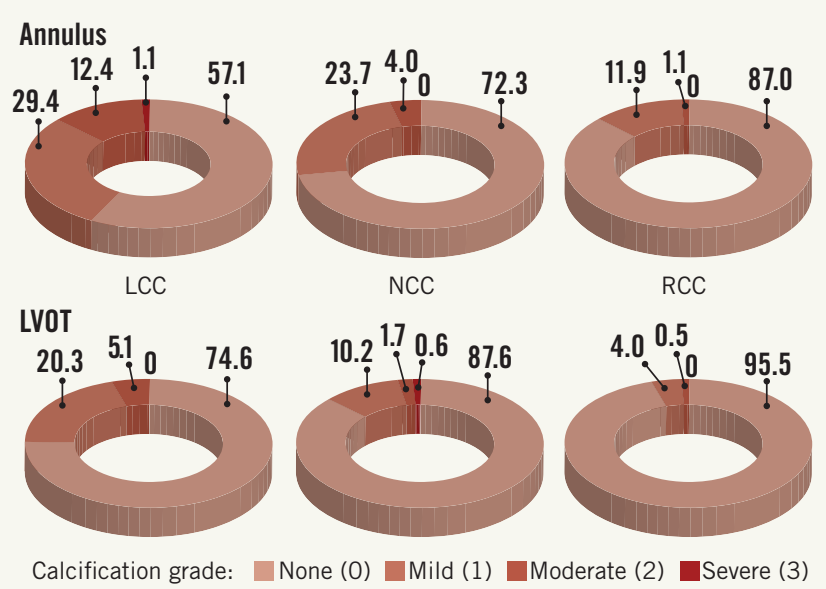

Figure 2. Prevalence of annulus and LVOT calcifications according to location and severity in percent. LCC: left coronary cusp; LVOT: left ventricular outflow tract; NCC: non-coronary cusp; $R C C$ : right coronary cusp 
Table 2. Baseline patient characteristics.

\begin{tabular}{|c|c|c|c|c|c|}
\hline & \multirow{2}{*}{$\begin{array}{c}\text { Total } \\
N=177\end{array}$} & \multicolumn{3}{|c|}{ Aortic regurgitation after implantation } \\
\hline & & & $\begin{array}{c}\text { None or mild } \\
n=122\end{array}$ & $\begin{array}{l}\text { Moderate or severe } \\
\quad n=55\end{array}$ & $p$-value \\
\hline \multicolumn{2}{|l|}{ Age (years) } & $82.2 \pm 5.8$ & $82.9 \pm 4.3$ & $81.5 \pm 7.4$ & 0.123 \\
\hline \multicolumn{2}{|c|}{ Female gender, $\mathrm{n}(\%)$} & $97(55 \%)$ & $74(61 \%)$ & $23(42 \%)$ & 0.023 \\
\hline \multicolumn{2}{|c|}{ Body mass index $\left(\mathrm{kg} / \mathrm{m}^{2}\right)$} & $25.8 \pm 4.8$ & $25.9 \pm 4.8$ & $24.9 \pm 3.8$ & 0.186 \\
\hline \multirow{4}{*}{$\begin{array}{l}\text { Cardiac risk } \\
\text { factors }\end{array}$} & Diabetes mellitus, $\mathrm{n}(\%)$ & $49(28 \%)$ & $35(29 \%)$ & $14(25 \%)$ & 0.719 \\
\hline & Hypercholesterolaemia, n (\%) & $107(61 \%)$ & $73(60 \%)$ & $34(62 \%)$ & 0.869 \\
\hline & Hypertension, n (\%) & $134(76 \%)$ & $93(76 \%)$ & $41(75 \%)$ & 0.851 \\
\hline & Current smoker, n (\%) & $22(12 \%)$ & $13(11 \%)$ & $9(16 \%)$ & 0.327 \\
\hline \multirow{10}{*}{$\begin{array}{l}\text { Past medical } \\
\text { history }\end{array}$} & Coronary artery disease, $\mathrm{n}(\%)$ & $120(68 \%)$ & $75(61 \%)$ & $35(64 \%)$ & 0.868 \\
\hline & Previous myocardial infarction, $\mathrm{n}(\%)$ & $27(15 \%)$ & $19(16 \%)$ & $8(15 \%)$ & 1.000 \\
\hline & Previous coronary artery bypass graft, $\mathrm{n}(\%)$ & $31(18 \%)$ & $22(18 \%)$ & $9(16 \%)$ & 0.835 \\
\hline & Previous percutaneous coronary intervention, $\mathrm{n}(\%)$ & $47(27 \%)$ & $31(25 \%)$ & $16(29 \%)$ & 0.713 \\
\hline & Previous stroke, n (\%) & $15(9 \%)$ & $10(8 \%)$ & $5(9 \%)$ & 1.000 \\
\hline & Peripheral vascular disease, $\mathrm{n}(\%)$ & $30(17 \%)$ & $20(16 \%)$ & $10(18 \%)$ & 0.829 \\
\hline & Atrial fibrillation, n (\%) & $52(29 \%)$ & $37(31 \%)$ & $15(28 \%)$ & 0.858 \\
\hline & Chronic obstructive pulmonary disease, n (\%) & $28(16 \%)$ & $15(12 \%)$ & $13(24 \%)$ & 0.073 \\
\hline & Renal dysfunction (eGFR <60 ml/min/1.73 m²) & $119(67 \%)$ & $83(68 \%)$ & $36(65 \%)$ & 0.733 \\
\hline & Pulmonary artery hypertension* & $53(30 \%)$ & $35(29 \%)$ & $18(33 \%)$ & 0.594 \\
\hline \multirow{2}{*}{$\begin{array}{l}\text { Risk } \\
\text { assessment }\end{array}$} & Logistic EuroSCORE (\%) & $23.3 \pm 13.2$ & $23.4 \pm 14.4$ & $23.3 \pm 10.6$ & 0.958 \\
\hline & STS score (\%) & $6.1 \pm 3.9$ & $6.3 \pm 4.3$ & $5.9 \pm 3.3$ & 0.490 \\
\hline
\end{tabular}

ejection fraction $(48.8 \pm 15.2 \%$ vs. $52.9 \pm 15.5 \%$; $=0.105)$. Patients with AR grade 2-4 had a larger annulus (perimeter: $78.7 \pm 6.9 \mathrm{~mm}$ vs. $72.9 \pm 6.4 \mathrm{~mm}$; $\mathrm{p}<0.001$; area: $475.8 \pm 84.1 \mathrm{~mm}^{2}$ vs. $409.9 \pm 72.6 \mathrm{~mm}^{2}$; $\mathrm{p}<0.001)$ at baseline and the TAVR prosthesis was less oversized $(11.6 \pm 11.4 \%$ vs. $13.7 \pm 10.0 \%$; $=0.001)$.

\section{Impact of calcification on post-implant aortic regurgitation}

Table 3 shows the distribution of annulus and LVOT calcification in patients with and without grade 2-4 post-implant aortic regurgitation. The overall calcification extent at both the annulus and the LVOT level was higher among patients with moderate to severe AR as opposed to patients with none or mild AR, with a positive association between overall calcification extent and prevalence of AR (Figure 3). There was a significant difference in the severity of calcification for the non-coronary cusp location between both groups, but no significant differences for the left and right coronary cusp locations for both the annular and the LVOT level (Table 3). Within the LVOT, the presence of any calcification as well as any moderate to severe calcification was higher among patients with more than mild AR compared to those with none to mild AR. Within the annulus, we observed a similar trend without reaching conventional levels of statistical significance. Multivariate regression analysis revealed that the overall annulus calcification (OR [95\% CI] 1.48 [1.10-2.00]; $\mathrm{p}=0.0106)$, the overall LVOT calcification (1.93 [1.262.96]; $\mathrm{p}=0.0026$ ), any moderate or severe LVOT calcification (5.37
[1.52-18.99]; $p=0.0092$ ), and asymmetric LVOT calcification were independent predictors of moderate to severe AR (Table 4).

\section{Discussion}

Our study demonstrates that calcifications within the annulus and LVOT are frequently observed in patients with severe aortic valve stenosis undergoing TAVR, and that both severity and distribution of calcification within the annulus and LVOT have a significant impact on the risk of significant aortic regurgitation immediately after TAVR prosthesis implantation.

Calcification of the aortic root assumes a central role in the pathophysiological process underlying degenerative aortic valve stenosis. The degenerative process typically begins and progresses within the leaflets, but may extend into surrounding regions during a later disease stage. Rosenhek and colleagues ${ }^{12}$ have proposed a grading system for aortic valve calcifications based on transthoracic echocardiographic findings (no calcification; mildly calcified [small isolated spots]; moderately calcified [multiple larger spots]; heavily calcified [extensive thickening and calcification of all cusps]), which has been accepted as a semi-quantitative tool to describe the overall amount of aortic valve calcification.

The advent of advanced imaging techniques such as MSCT has improved detection of aortic valve calcifications and allows for a quantitative analysis of the extent and distribution of calcifications $^{13,14}$. Several studies have identified calcification of the aortic valve as an independent predictor of aortic regurgitation, the need 
Table 3. Annulus and LVOT calcification according to aortic regurgitation immediately after TAVR.

\begin{tabular}{|c|c|c|c|}
\hline & \multicolumn{3}{|c|}{ Aortic regurgitation after implantation } \\
\hline & $\begin{array}{l}\text { None or mild } \\
\qquad n=122\end{array}$ & $\begin{array}{c}\text { Moderate or } \\
\text { severe } \\
n=55\end{array}$ & $p$-value \\
\hline \multicolumn{4}{|l|}{ Aortic annulus } \\
\hline Non-coronary cusp & & & 0.013 \\
\hline none & $95(78 \%)$ & $33(60 \%)$ & \\
\hline mild & $25(20 \%)$ & $17(31 \%)$ & \\
\hline moderate & $2(2 \%)$ & $5(9 \%)$ & \\
\hline severe & $0(0 \%)$ & $0(0 \%)$ & \\
\hline Left coronary cusp & & & 0.471 \\
\hline none & $74(61 \%)$ & $27(49 \%)$ & \\
\hline mild & $34(28 \%)$ & $18(33 \%)$ & \\
\hline moderate & $13(11 \%)$ & $9(16 \%)$ & \\
\hline severe & $1(1 \%)$ & $1(2 \%)$ & \\
\hline Right coronary cusp & & & 0.177 \\
\hline none & $110(90 \%)$ & $44(80 \%)$ & \\
\hline mild & $11(9 \%)$ & $10(18 \%)$ & \\
\hline moderate & $1(1 \%)$ & $1(2 \%)$ & \\
\hline severe & $0(0 \%)$ & $0(0 \%)$ & \\
\hline Any calcification & $68(56 \%)$ & $39(71 \%)$ & 0.068 \\
\hline $\begin{array}{l}\text { Any moderate or severe } \\
\text { calcification }\end{array}$ & 17 (14\%) & $13(24 \%)$ & 0.131 \\
\hline Overall grade & $1(0-1)$ & $1(0-2)$ & 0.008 \\
\hline \multicolumn{4}{|l|}{ LVOT } \\
\hline Non-coronary cusp & & & 0.011 \\
\hline none & $112(92 \%)$ & $43(78 \%)$ & \\
\hline mild & $10(8 \%)$ & $8(15 \%)$ & \\
\hline moderate & $0(0 \%)$ & $3(5 \%)$ & \\
\hline severe & $0(0 \%)$ & $1(2 \%)$ & \\
\hline Left coronary cusp & & & 0.109 \\
\hline none & 96 (79\%) & $36(65 \%)$ & \\
\hline mild & 22 (18\%) & $14(25 \%)$ & \\
\hline moderate & $4(3 \%)$ & $5(9 \%)$ & \\
\hline severe & $0(0 \%)$ & $0(0 \%)$ & \\
\hline Right coronary cusp & & & 0.255 \\
\hline none & $118(97 \%)$ & $51(93 \%)$ & \\
\hline mild & $4(3 \%)$ & $3(5 \%)$ & \\
\hline moderate & $0(0 \%)$ & $1(2 \%)$ & \\
\hline severe & $0(0 \%)$ & $0(0 \%)$ & \\
\hline Any calcification & $34(28 \%)$ & $29(53 \%)$ & 0.002 \\
\hline $\begin{array}{l}\text { Any moderate or severe } \\
\text { calcification }\end{array}$ & $4(3 \%)$ & $9(16 \%)$ & 0.004 \\
\hline Overall grade & $0(0-1)$ & $1(0-1)$ & 0.004 \\
\hline
\end{tabular}

for post-dilation, the need for pacemaker implantation, and the risk of annulus rupture in patients undergoing TAVR ${ }^{1,2,7-10,15,16}$. While these findings are well established for the overall extent of valve calcification, little is known about the spatial distribution of calcifications within the different levels of the aortic root, including
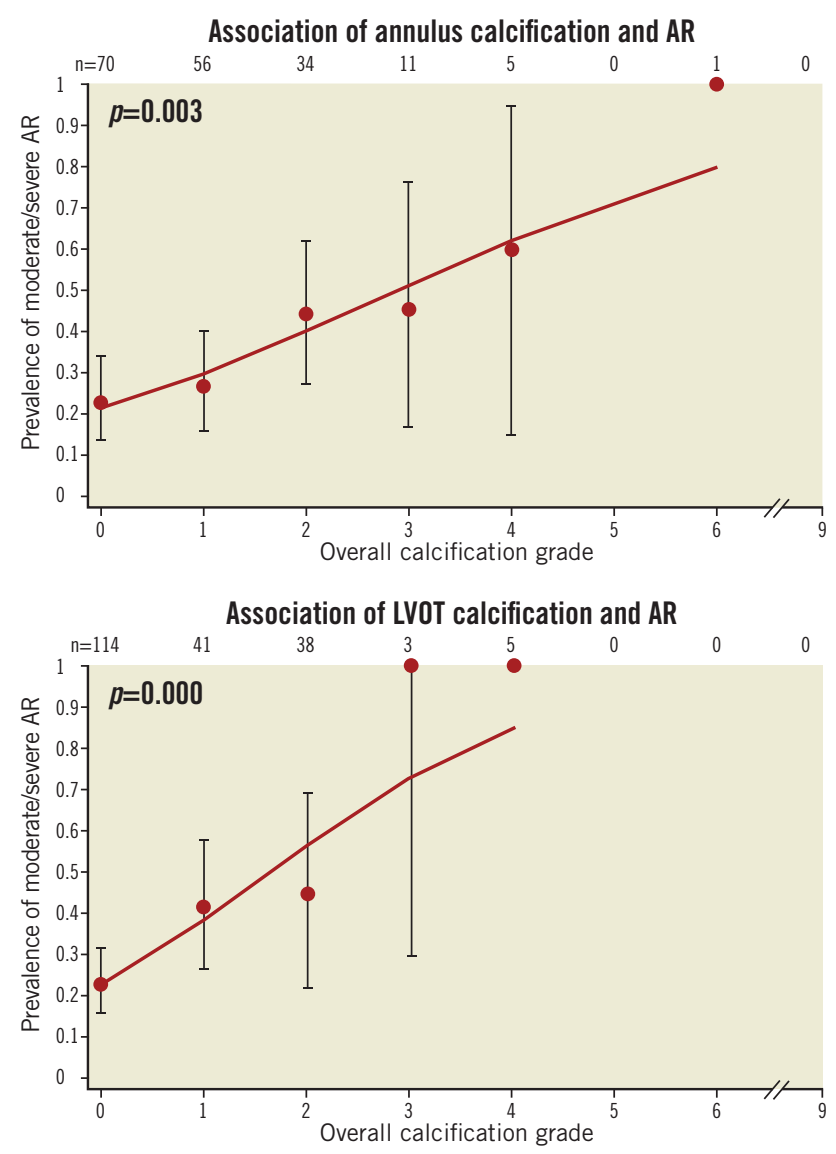

Figure 3. Association of annulus and left ventricular outflow tract calcification and post-implantation aortic regurgitation. AR: aortic regurgitation

the LVOT, the annulus, the aortic leaflets, the sinus of Valsalva, the sinotubular junction and the adjacent ascending aorta, and their clinical impact. Based on geometric considerations, calcifications above the leaflets are irrelevant for device performance in patients

Table 4. Multivariate analysis of annulus and LVOT calcification and impact on AR immediately after TAVR.

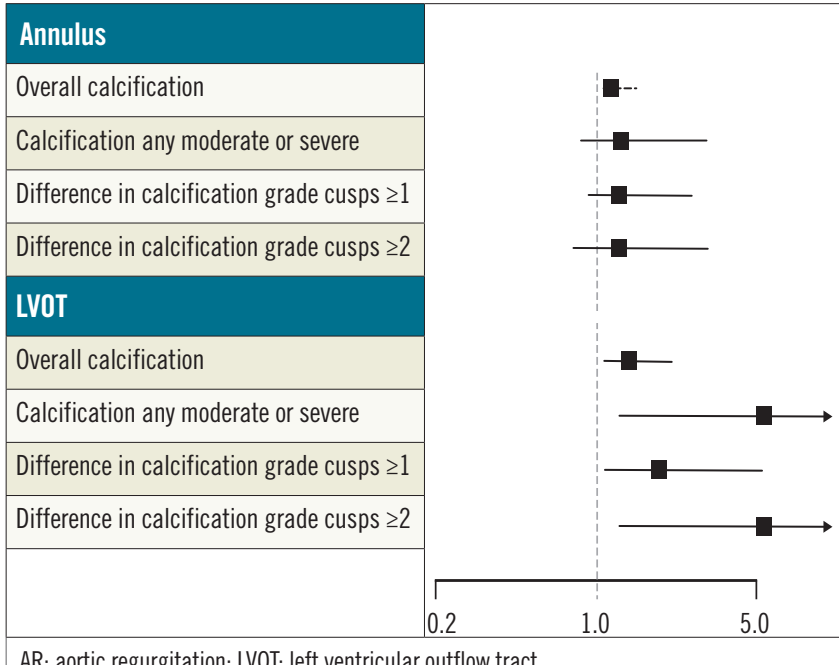


undergoing TAVR. Calcifications within the leaflets interact with the device, but are typically displaced into the sinus which is unproblematic in case of a sufficiently large coronary sinus. Leaflet calcifications are unlikely to cause AR if the anchoring and sealing remains complete within the annulus or LVOT, which is the acting principle of currently available TAVR devices. Conversely, we hypothesised that calcifications within the annulus and LVOT may be relevant predictors of AR immediately after TAVR with currently used devices as they impair complete sealing. Based on the classification proposed in this manuscript, we were able to analyse the frequency, extent, distribution and impact of local calcification within the annulus and LVOT among patients with severe aortic valve stenosis undergoing TAVR.

\section{Frequency and spatial distribution of aortic valve calcification}

Aortic annulus calcification is frequent and was observed in approximately two-thirds of patients undergoing TAVR in the present study. In one-third of the overall population, these calcifications further extended into the LVOT. These findings partially corroborate an earlier report by Rivard et $\mathrm{al}^{17}$, who analysed 33 patients with severe aortic valve stenosis, in whom annular calcifications were present in all analysed subjects, while LVOT calcifications extending into the membranous part of the interventricular septum were present in $36 \%$ and towards the anterior mitral leaflet in $42 \%$ of patients. The fact that one third of patients in our study did not present with annular calcifications may be surprising, but is largely the result of the new imaging precision provided by modern visualisation tools which help in the clear separation of different aspects of the aortic root in an unsurpassed way. With this imaging precision, calcifications within the leaflets, which were present in all but three patients, can be nicely distinguished from calcifications within the annulus and LVOT.

\section{Impact of annulus and LVOT calcification on aortic regurgitation after TAVR}

Local calcifications within the annulus and even more importantly within the LVOT increase the risk of post-implant AR. Three recent studies of 55 to 105 TAVR patients ${ }^{10,18,19}$, with focus on annular calcifications graded semi-quantitatively, demonstrated an association between overall annular calcification and post-procedural AR. Our data in 177 patients with utilisation of a cusp-specific classification system not only confirm but importantly extend these findings, and specific spatial distribution patterns were found highly predictive of AR immediately after TAVR. In the present study, the sum of calcifications of the annulus as well as the LVOT emerged as independent predictors of more than mild AR immediately after implantation of a TAVR device. Moreover, we observed that calcifications located in the LVOT as opposed to the annulus played a more important role, and that grade 2 and 3 (moderate and severe) calcifications and asymmetric calcifications within the LVOT were associated with a 2.5 to 5.4-fold increased risk of significant AR immediately after prosthesis implantation. In addition, the severity of calcification of the noncoronary cusp location was associated with significant AR directly after TAVR device implantation. It therefore appears prudent during the TAVR screening process to focus not only on overall valve calcification but also on the spatial distribution of calcifications in the aortic root and particularly within the annulus and LVOT region, which independently predicts immediate post-procedural AR. Larger studies are required to evaluate reliably the impact of localised calcifications on additional rare events such as annulus and LVOT rupture. However, the understanding of various calcification patterns and the given calcification distribution in a particular patient may guide device selection and sizing in daily clinical practice, resulting in an improved and predictable procedural outcome.

\section{Limitations}

This study consists of a selective TAVR population, and the results in terms of extent and distribution of calcifications may not be extrapolated to the overall population of patients with aortic valve stenosis. According to local standard, the majority of TAVR procedures were performed with conscious sedation without periprocedural transoesophageal echocardiographic guidance. Therefore, AR after implantation of the TAVR prosthesis was assessed by aortic root angiography using the established criteria suggested by Sellers in 1964, which is known to be less sensitive and precise than echocardiography. However, this strategy reflects current common practice in many experienced TAVR sites. As angiographic assessment of $A R$ does not allow differentiation between paravalvular and valvular AR, these two entities were not separately considered in the analysis. This paper did not focus on leaflet calcifications, but on annular and LVOT calcifications. However, the overall extent of valve calcification semi-quantitatively assessed, similar to the Rosenhek score ${ }^{14}$, has been considered in the multivariate predictor analysis. Finally, the number of patients with more than mild calcifications in the annulus and particularly the LVOT is small in this study, which might affect the analysis and limit the data interpretation.

\section{Impact on daily practice}

Calcifications of the aortic annulus and left ventricular outflow tract are frequent in patients undergoing TAVR, and both the distribution and the severity of calcifications appear to be independent predictors of aortic regurgitation immediately after device implantation. Therefore, pre-procedural TAVR screening should include a detailed calcification assessment not only of the leaflets but also of the annulus and particularly the left ventricular outflow tract, and results may guide device type and size selection.

\section{Conflict of interest statement}

L. Buellesfeld is a consultant and proctor for Medtronic and Edwards Lifesciences. P. Wenaweser is a proctor for and receives honoraria from Medtronic and Edwards Lifesciences. S. Windecker has received lecture and consultant fees from Edwards Lifesciences and Medtronic. The other authors have no conflicts of interest to declare. 


\section{References}

1. Barbanti M, Yang TH, Rodès Cabau J, Tamburino C, Wood DA, Jilaihawi H, Blanke P, Makkar RR, Latib A, Colombo A, Tarantini G, Raju R, Binder RK, Nguyen G, Freeman M, Ribeiro HB, Kapadia S, Min J, Feuchtner G, Gurtvich R, Alqoofi F, Pelletier M, Ussia GP, Napodano M, de Brito FS Jr, Kodali S, Norgaard BL, Hansson NC, Pache G, Canovas SJ, Zhang H, Leon MB, Webb JG, Leipsic J. Anatomical and procedural features associated with aortic root rupture during balloon-expandable transcatheter aortic valve replacement. Circulation. 2013;128:244-53.

2. Hayashida K, Bouvier E, Lefèvre T, Hovasse T, Morice MC, Chevalier B, Romano M, Garot P, Farge A, Donzeau-Gouge P, Cormier B. Potential mechanism of annulus rupture during transcatheter aortic valve implantation. Catheter Cardiovasc Interv. 2013;82: E742-6.

3. Généreux P, Head SJ, Hahn R, Daneault B, Kodali S, Williams MR, van Mieghem NM, Alu MC, Serruys PW, Kappetein AP, Leon MB. Paravalvular leak after transcatheter aortic valve replacement: the new Achilles' heel? A comprehensive review of the literature. J Am Coll Cardiol. 2013;61:1125-36.

4. Kodali SK, Williams MR, Smith CR, Svensson LG, Webb JG, Makkar RR, Fontana GP, Dewey TM, Thourani VH, Pichard AD, Fischbein M, Szeto WY, Lim S, Greason KL, Teirstein PS, Malaisrie SC, Douglas PS, Hahn RT, Whisenant B, Zajarias A, Wang D, Akin JJ, Anderson WN, Leon MB; PARTNER Trial Investigators. Two-year outcomes after transcatheter or surgical aortic-valve replacement. N Engl J Med. 2012;366:1686-95.

5. Sinning JM, Hammerstingl C, Vasa-Nicotera M, Adenauer V, Lema Cachiguango SJ, Scheer AC, Hausen S, Sedaghat A, Ghanem A, Müller C, Grube E, Nickenig G, Werner N. Aortic regurgitation index defines severity of peri-prosthetic regurgitation and predicts outcome in patients after transcatheter aortic valve implantation. $J$ Am Coll Cardiol. 2012;59:1134-41.

6. Moat NE, Ludman P, de Belder MA, Bridgewater B, Cunningham AD, Young CP, Thomas M, Kovac J, Spyt T, MacCarthy PA, Wendler O, Hildick-Smith D, Davies SW, Trivedi U, Blackman DJ, Levy RD, Brecker SJ, Baumbach A, Daniel T, Gray H, Mullen MJ. Long-term outcomes after transcatheter aortic valve implantation in high-risk patients with severe aortic stenosis: the U.K. TAVI (United Kingdom Transcatheter Aortic Valve Implantation) Registry. J Am Coll Cardiol. 2011;58:2130-8.

7. John D, Buellesfeld L, Yuecel S, Mueller R, Latsios G, Beucher H, Gerckens U, Grube E. Correlation of Device landing zone calcification and acute procedural success in patients undergoing transcatheter aortic valve implantations with the self-expanding CoreValve prosthesis. JACC Cardiovasc Interv. 2010;3:233-43.

8. Ewe SH, Ng AC, Schuijf JD, van der Kley F, Colli A, Palmen M, de Weger A, Marsan NA, Holman ER, de Roos A, Schalij MJ, Bax JJ, Delgado V. Location and severity of aortic valve calcium and implications for aortic regurgitation after transcatheter aortic valve implantation. Am J Cardiol. 2011;108:1470-7.
9. Koos R, Mahnken AH, Dohmen G, Brehmer K, Günther RW, Autschbach R, Marx N, Hoffmann R. Association of aortic valve calcification severity with the degree of aortic regurgitation after transcatheter aortic valve implantation. Int J Cardiol. 2011;150:142-5.

10. Feuchtner G, PlankF, Bartel T, Mueller S, Leipsic J, SchachnerT, Müller L, Friedrich G, Klauser A, Grimm M, Bonaros N. Prediction of paravalvular regurgitation after transcatheter aortic valve implantation by computed tomography: value of aortic valve and annular calcification. Ann Thorac Surg. 2013;96:1574-80.

11. Delgado V, Ng AC, Schuijf JD, van der Kley F, Shanks M, Tops LF, van de Veire NR, de Roos A, Kroft LJ, Schalij MJ, Bax JJ. Automated assessment of the aortic root dimensions with multidetector row computed tomography. Ann Thorac Surg. 2011;91:716-23.

12. Rosenhek R, Binder T, Porenta G, Lang I, Christ G, Schemper M, Maurer G, Baumgartner H. Predictors of outcome in severe, asymptomatic aortic stenosis. NEngl JMed. 2000;343:611-7.

13. Willmann JK, Weishaupt D, Lachat M, Kobza R, Roos JE, Seifert B, Lüscher TF, Marincek B, Hilfiker PR. Electrocardiographically gated multi-detector row CT for assessment of valvular morphology and calcification in aortic stenosis. Radiology. 2002;225:120-8.

14. Budoff MJ, Takasu J, Katz R, Mao S, Shavelle DM, O'Brien KD, Blumenthal RS, Carr JJ, Kronmal R. Reproducibility of CT measurements of aortic valve calcification, mitral annulus calcification, and aortic wall calcification in the multi-ethnic study of atherosclerosis. Acad Radiol. 2006;13:166-72.

15. Schultz C, Rossi A, van Mieghem N, van der Boon R, Papadopoulou SL, van Domburg R, Moelker A, Mollet N, Krestin G, van Geuns RJ, Nieman K, de Feyter P, Serruys PW, de Jaegere P. Aortic annulus dimensions and leaflet calcification from contrast MSCT predict the need for balloon post-dilatation after TAVI with the Medtronic CoreValve prosthesis. EuroIntervention. 2011;7: 564-72.

16. Latsios G, Gerckens U, Buellesfeld L, Mueller R, John D, Yuecel S, Syring J, Sauren B, Grube E. "Device landing zone" calcification, assessed by MSCT, as a predictive factor for pacemaker implantation after TAVI. Catheter Cardiovasc Interv. 2010;76: 431-9.

17. Rivard AL, Bartel T, Bianco RW, O’Donnell KS, Bonatti J, Dichtl W, Cury RC, Feuchtner GM. Evaluation of aortic root and valve calcifications by multi-detector computed tomography. J Heart Valve Dis. 2009;18:662-70.

18. Marwan M, Achenbach S, Ensminger SM, Pflederer T, Ropers D, Ludwig J, Weyand M, Daniel WG, Arnold M. CT predictors of post-procedural aortic regurgitation in patients referred for transcatheter aortic valve implantation: an analysis of 105 patients. Int J Cardiovasc Imaging. 2013;29:1191-8.

19. Masri A, Schoenhagen P, Svensson L, Kapadia SR, Griffin BP, Tuzcu EM, Desai MY. Dynamic characterization of aortic annulus geometry and morphology with multimodality imaging: predictive value for aortic regurgitation after transcatheter aortic valve replacement. J Thorac Cardiovasc Surg. 2014;147:1847-54. 